\title{
SUSTAINABLE CONSTRUCTION SUPPLIER SELECTION BY A MULTIPLE CRITERIA DECISION-MAKING METHOD WITH HESITANT LINGUISTIC INFORMATION
}

\author{
Huchang Liao', Ruxue Ren², Jurgita Antucheviciene', \\ Jonas Saparauskas ${ }^{4}$, Abdullah Al-Barakati ${ }^{5}$
}

\footnotetext{
1 Sichuan University, Business School, China, ORCID: 0000-0001-8278-3384, liaohuchang@163.com; Sichuan University, Business School, China, ORCID: 0000-0002-9246-849x, renruxuerrx@163.com;

Vilnius Gediminas Technical University, Faculty of Civil Engineering, Department of Construction Management and Real Estate, Lithuania, ORCID: 0000-0002-1734-3216, jurgita.antucheviciene@vgtu.It;

4 Vilnius Gediminas Technical University, Faculty of Civil Engineering, Department of Construction Management and Real Estate, Lithuania, ORCID: 0000-0003-3685-7754, jonas.saparauskas@vgtu.It;

$5 \quad$ King Abdulaziz University, Faculty of Computing and Information Technology, Saudi Arabia, ORCID: 0000-00026784-3278, aaalbarakati@kau.edu.sa.
}

\begin{abstract}
Within the context of resource constraints and ecological environment imbalance, the adoption of green suppliers can help construction enterprises achieve sustainable development and improve their competitiveness. The selection of sustainable construction suppliers is a multi-criteria decision-making problem since multiple factors should be considered. The increasingly complex decision-making environment makes it difficult for evaluators to give accurate evaluation values. In this regard, the hesitant fuzzy linguistic term set is a qualitative evaluation tool to represent the comprehensive linguistic evaluation values of experts by considering the hesitancy behaviors of experts. In this paper, a scientific multi-criteria decision-making model based on the improved Stepwise Weight Assessment Ratio Analysis (SWARA) method and the double normalizationbased multi-aggregation (DNMA) method in the hesitant fuzzy linguistic environment is proposed. A new distance measure is proposed to measure the differences between hesitant fuzzy linguistic term sets with different lengths without changing the original evaluation information of experts. The proposed distance measure is applied to the proposed multi-criteria decision-making model. After improving the calculation steps of the traditional SWARA method, we can determine the weights of criteria effectively through our proposed model. To verify the applicability of the proposed method, we implement it to select sustainable building suppliers. The effectiveness of the method is verified by sensitivity analysis. We also compare the results obtained by our method and those derived by the Weight Aggregated Sum Product ASsessment (WASPAS) method and the Technique for Order Preference by Similarity to an Ideal Solution (TOPSIS) method. The proposed method have a strong applicability to solve the sustainability-related decision problems given that it can effectively determine the weights of criteria and flexibly meet the needs of decision-makers by adjusting the coefficient.
\end{abstract}

Keywords: Sustainable supplier, Multiple Criteria Decision Making (MCDM), distance measure, Stepwise Weight Assessment Ratio Analysis (SWARA), Double Normalization-based MultiAggregation (DNMA) method.

JEL Classification: Q48, Q56, C91.

APA Style Citation: Liao, H. C., Ren, R. X., Antucheviciene, J., Šaparauskas, J., \& Al-Barakati, A. (2020). Sustainable Construction Supplier Selection by a Multiple Criteria Decision-making Method with Hesitant Linguistic Information. E\&M Economics and Management, 23(4), 119-136. https://doi.org/10.15240/tul/001/2020-4-008 


\section{Problem Definition}

The constriction of global resources and the sustained growth of population bring resources pressure to society. At the same time, the problem of environmental pollution and ecological imbalance cannot be ignored. In 2008, the United Nations Environment Programme launched the "Green Economy" initiative to integrate the concept of green and sustainable development into economic development. In this context, resource conservation, environmental protection and sustainable development are the best choices in this era. The construction industry is the pillar industry of Chinese economy. It is important for the construction industry to implement sustainable development. Faced with the pressure of resources and higher environmental requirements, green supply chain is an important means to enhance the environmental friendliness of construction industry and realize the rapid development of enterprises (Beamon, 1999; Ansari \& Kant, 2017). The implementation of green supply chain management can help the construction industry effectively integrate external resources and maximize the economic, environmental and social benefits of the construction industry. Therefore, in today's massive construction period, the implementation of green supply chain in construction industry is imperative. To achieve green production, it is important to select suppliers of building materials from the perspective of sustainable development.

The selection of construction suppliers is a multi-criteria decision-making (MCDM) problem since experts need to evaluate alternatives according to multiple criteria and eventually rank the alternatives. In the expert evaluation process, the hesitant fuzzy linguistic term set (HFLTS) is a good information representation tool (Rodríguez et al., 2012). Scholars have studied various MCDM methods within the context of HFLTSs (Beg \& Rashid, 2013; Liao et al., 2015a; Tuysuz \& Berna, 2017; Ren et al., 2019). At present, the sustainable supplier selection with MCDM models in the HFL environment has been studied in many aspects, such as the furniture supplier selection (Dos Santos et al., 2018), electronic manufacturing company supplier selection (Chatterjee et al., 2018), and third-party reverse logistics supplier selection (Tosarkani \& Amin, 2018). However, few studies were focused on the supplier selection for construction enterprises in the HFL environment. Given the advantages of HFLTSs as an evaluation tool (Liao et al., 2018) and the research advances of sustainable building supplier selection, it is necessary to propose an MCDM model for green building supplier selection in the HFL environment.

When evaluating with HFLTSs, qualitative information is usually processed and transformed into quantitative information. To calculate the distance between hesitant fuzzy linguistic elements (HFLEs), scholars (Liao et al., 2014; Liao \& Xu, 2020) developed different distance measures based on Euclidean distance, Hamming distance, Hausdorff distance, cosine distance and their weighted forms. In practice, two HFLEs usually have different numbers of linguistic terms. The aforementioned methods added maximum or minimum linguistic term to the shorter HFLE according to the risk preference of an expert to make the compared HFLEs have the same length, and then calculated their distances. This extending strategy may be contrary to the original perceptions of experts (Liao et al., 2020). Considering this, a new distance measure is developed in this study based on the Willcoxon two-sample test method (Gehan, 1965).

The Stepwise Weight Assessment Ratio Analysis (SWARA) method can be used to evaluate the weights of criteria by establishing the links between criteria and evaluating the importance differences between criteria (Keršulienè et al., 2010). Compared with other criteria weight determination methods, the SWARA method is not difficult to operate and the computational complexity is low (Zolfani et al., 2018). However, the traditional SWARA method has some limitations. For example, the process of establishing the relationships between criteria is inappropriate since small differences between criteria cannot be reflected in the calculation process (see Section 3.1 for details). To make a better use of this method, the calculation steps of the traditional SWARA method are improved in this paper.

In summary, this study dedicates to achieving the following innovative contributions: 1. The calculation process of the SWARA method is improved to show the importance difference between criteria clearly. Combining the improved SWARA method with the Double Normalization-based 
Multiple Aggregation (DNMA) method (Liao \& Wu, 2020), a scientific and efficient decision model for solving MCDM problems is formed.

2. In view of the shortcomings of existing distance measures between hesitant fuzzy linguistic evaluation values with different lengths, a new distance measure is proposed to improve the accuracy of the calculation results and ensure the integrity of the original evaluation information.

3. The new distance measure is applied to the integrated MCDM method to improve the accuracy of calculation. Then, this method is used to solve the problem of supplier selection. It not only verifies the applicability of this method, but also provides insights for the research of sustainable building supplier selection.

\section{Preliminaries}

\subsection{Literature Review on MCDM Methods for Sustainable Construction Supplier Selection}

Green supply chain integrates green manufacturing theory into supply chain management. In the whole product life cycle involving suppliers, producers and retailers, it strives to make products from processing, packaging, warehousing, transportation to scrap disposal, reducing the negative impact on environment, and improving the efficiency of resource utilization (Beamon, 1999). This concept fits well with the theme of resource conservation and environmental protection all over the world. Under this background, enterprises must consider environmental protection factors while transforming resources to gain benefits. Only in this way can they gain great competitive advantages. Introducing the concept of green supply chain into the development of enterprises can not only alleviate the pressure of resources, but also help enterprises achieve sustainable development.

Supplier selection is the source of supply chain, an important step to improve the efficiency of supply chain, and also the basis of realizing green supply chain from the source. At this stage, the concept of green supply chain and the skills of green supplier selection have penetrated into many fields. Keshavarz Ghorabaee et al. (2016) used interval fuzzy sets to express qualitative information in green supplier selection problems, and implemented the extended Weight Aggregated Sum Product ASsessment (WASPAS) method to rank alternatives. Chatterjee et al. (2018) integrated the DEcision-MAking Trial and Evaluation Laboratory (DEMATEL) and Analytic Network Process (ANP) methods with rough sets, and then applied it to solve the green supplier selection problem for an electronic manufacturing company. Dos Santos et al. (2018) selected ten actual cases of supplier selection of large furniture enterprises, using the fuzzy-Technique for Order Preference by Similarity to an Ideal Solution (fuzzyTOPSIS) method to evaluate the performance of suppliers. Tosarkani and Amin (2018) used the fuzzy network analysis and multi-objective mixed integer linear programming model to find the non-dominant solution, which provides a reference for solving the third-party reverse logistics supplier selection problem. Lo et al. (2018) established an integrated model for green supplier selection and order allocation under the dynamic cooperative environment, which used the Best Worst Method (BWM) to obtain the weights of green indicators and the improved fuzzy TOPSIS and fuzzy multi-objective linear programming method evaluation to handle the uncertain information. Wu et al. (2019) established an MCDM model based on the BWM and VIKOR methods with interval type-2 fuzzy values to solve the rate color supply chain management problem. Rouyendegh et al. (2020) combined intuitionistic fuzzy sets with the TOPSIS method to solve the supplier selection problem.

Introducing the concept of green supply chain into the construction industry is to implement the concept of environmental protection in the whole construction life cycle involving procurement, construction, operation, maintenance, and recycling, and achieve efficient control over logistics, information flow and capital flow. The procurement of building materials is the basis of the whole life cycle of construction. The selection of green building suppliers is an MCDM problem. There are some researches on the selection of building suppliers. Seth et al. (2017) took the supply chain of large-scale residential construction projects as a research object, and then analyzed the impact of market competition on supplier selection and evaluation. Yin and $\mathrm{Li}$ (2018) transformed the dynamic bilateral 
matching model based on intuitionistic fuzzy sets into a single objective optimization model by a linear weighting method to match the supply and demand of green buildings. Wang et al. (2017) modeled the information integration in the selection of suppliers for elastic buildings, and evaluated the suppliers with Analytic Hierarchy Process (AHP) and grey relational analysis. Estimating the roughness using the full consistency method, Matiqi et al. (2019) obtained the sustainability criteria for supplier selection in construction enterprises, and matched suppliers with the COmplex PRoportional ASsessment of alternatives (COPRAS) method.

Even though scholars and practitioners have paid attention to the green building supplier management, there is little research on the selection of green building suppliers under the hesitant fuzzy linguistic environment. Evaluations in the hesitant fuzzy linguistic environment are more consistent with the evaluation habits of experts and thus are conducive to maintaining the integrity of information. In addition, considering the complexity of decision-making environment and the hesitancy of experts' evaluations, it is needed to develop an enhanced MCDM method under the HFL environment for green supplier selection.

\subsection{Hesitant Fuzzy Linguistic Term Set}

Due to the limitation of people's knowledge and experience and the uncertainty of objective things, experts sometimes fail to give precise evaluation values in a decision-making process. Zadeh (1965) put forward the fuzzy set theory, which expanded the research scopes of various fields in modern society from precision to fuzzification. In actual decisionmaking process, language, as the carrier of qualitative evaluation, is the most commonly used representation tool. Taking into account the evaluation habits and the hesitancy of experts in the evaluation process, Rodríguez et al. (2012) introduced the concept of hesitant fuzzy linguistic term set (HFLTS) as an ordered finite subset of consecutive linguistic terms of a linguist term set (LTS). The HFLTS can store more evaluation information and reduce information omission. A new definition of HFLTS was later given by Liao et al. (2015b) to facilitate calculation and understanding.
Definition 1 (Liao et al., 2015b): Let $x_{i} \in X(i=1,2, \ldots, n)$ be fixed and $S=\left\{s_{\alpha} \mid \alpha=-\tau\right.$, $\ldots,-1,0,1, \ldots, \tau\}$ be an LTS. $H_{s}$ is an HFLTS on $X$ with $. H_{S}=\left\{<x_{i}, h_{s}\left(x_{i}\right)>\mid x_{i} \ldots X\right\}$, where $. h_{s}\left(x_{i}\right)=\left\{s_{\phi l}\left(x_{i}\right) \mid s_{\phi l}\left(x_{i}\right) \in S, l=1,2, \ldots, L\right\} \ldots$ is a set of elements in $S$, which is called an HFLE.

The score of an HFLE was defined by Zhang and Wu (2014) as:

$$
\rho\left(h_{S}\right)=\frac{1}{L} \sum_{l=1}^{L} \frac{\varphi_{l}}{2 \tau}
$$

\subsection{Stepwise Weight Assessment Ratio Analysis (SWARA)}

SWARA, proposed by Keršulienè et al. (2010), is a method to determine the weights of criteria. It has been applied in many fields, such as building, management, manufacturing, to assist decision-making (Ruzgys et al., 2014; Aghdaie et al., 2013; Zarbakhshnia et al., 2018). This method takes the preferences of experts or interest groups for the importance ratio of criteria as a reference basis, and obtains the final weights by comparing the importance of criteria. It has several special characteristics. Firstly, the process of criteria comparison combines the knowledge and experience of experts and provides an opportunity to estimate the difference of criteria weights. Secondly, to obtain criteria weights, the limited number of comparisons used in this method save time and operation cost compared with other classical weight-determining methods. Suppose that the importance of criteria set $C=\left\{c_{j} \mid j=1,2, \ldots, n\right\}$ are judged by experts or interest groups, and the ordered criteria set $\hat{C}=\left\{\hat{c}_{j} \mid j=1,2, \ldots, n\right\}$ is obtained according to the mean of opinions. Then, the criteria are weighted by calculating their importance. The calculation process is shown in Tab. 1.

\subsection{Double Normalization-based Multi-aggregation (DNMA) Method}

DNMA method, proposed by Liao and Wu (2020), is an MCDM method which considers objectives, benefits and costs comprehensively. To eliminate the deviation and information loss caused by single normalization method, the DNMA method incorporates linear normalization and vector normalization in the process. To cope with different decision scenarios and needs, this method uses three aggregation models to get the final utility values. The specific calculation steps of this method are as follows: 


\section{Tab. 1: Calculation process for criteria weights}

\begin{tabular}{c|c|c|c|c} 
Criteria & $\begin{array}{c}\text { Comparative importance } \\
\text { of average value } \xi_{j}\end{array}$ & $\begin{array}{c}\text { Coefficient } \\
K_{j}=\xi_{j}+1\end{array}$ & $\begin{array}{c}\text { Recalculated weight } \\
w_{j}=w_{j-1} / K_{j}\end{array}$ & $\begin{array}{c}\text { Weight } \\
q_{j}=w_{j} / \sum w_{j}\end{array}$ \\
\hline$\hat{c}_{1}$ & - & 1 & 1 & $q_{1}$ \\
\hline$\hat{c}_{2}$ & $\xi_{2}$ & $K_{2}$ & $w_{2}$ & $q_{2}$ \\
\hline$\vdots$ & $\vdots$ & $\vdots$ & $\vdots$ & $\vdots$ \\
\hline$\hat{c}_{n}$ & $\xi_{n}$ & $K_{n}$ & $w_{n}$ & $q_{n}$ \\
\hline
\end{tabular}

Source: Keršulienè et al. (2010)

For the evaluation value $x_{i j}$ of alternative $a_{i}$ under criterion $c_{j}$, by linear normalization:

$$
\hat{x}_{i j}=1-\frac{\left|x_{i j}-r_{j}\right|}{\max _{i}\left|x_{i j}-r_{j}\right|}
$$

By vector normalization:

$$
\tilde{x}_{i j}=1-\frac{\left|x_{i j}-r_{j}\right|}{\sqrt{\sum_{i=1}^{m}\left(x_{i j}\right)^{2}+\left(r_{j}\right)^{2}}}
$$

where $r_{j}=\left\{\begin{array}{l}\max _{i} x_{i j}, \text { if } c_{j} \text { is an benefit criterion } \\ \operatorname{minx}_{i} x_{i j}, \text { if } c_{j} \text { is a cost criterion }\end{array}\right.$.

Let $w_{j}$ represent the weight of $c_{j}$. The complete compensatory model (CCM) and uncompensatory model (UCM) are calculated as:

$$
\begin{aligned}
& u_{1}\left(a_{i}\right)=\sum_{j=1}^{n} w_{j} \hat{x}_{i j}, \text { for } i=1,2, \cdots, m \\
& u_{2}\left(a_{i}\right)=\sum_{j=1}^{n} \max _{j} w_{j}\left(1-\hat{x}_{i j}\right) \\
& \text { for } i=1,2, \cdots, m
\end{aligned}
$$

Then, two ranks of $a_{i}, r_{1}\left(a_{i}\right)$, and $r_{2}\left(a_{i}\right)$, are obtained, in descending and ascending orders of $u_{1}\left(a_{i}\right)$ and $u_{2}\left(a_{i}\right)$, respectively.

To reflect the quality of original values, an incomplete compensatory model (ICM) is used on the basis of vector normalization:

$$
u_{3}\left(a_{i}\right)=\prod_{j}\left(\tilde{x}_{i j}\right)^{w_{j}}, \text { for } i=1,2, \cdots, m
$$

Then, the third type of rank, $r_{3}\left(a_{i}\right)$, is obtained in descending order of $u_{3}\left(a_{i}\right)$.

The comprehensive utility values are obtained by synthesizing the utility values of CCM, UCM and ICM and the subordinate ranks of alternatives:

$$
\begin{aligned}
& S_{i}=\sqrt{\varphi\left(\frac{u_{1}\left(a_{i}\right)}{\sqrt{\sum_{i=1}^{m}\left(u_{1}\left(a_{i}\right)\right)^{2}}}\right)^{2}+(1-\varphi)\left(\frac{m-r_{1}\left(a_{i}\right)+1}{m(m+1) / 2}\right)^{2}}- \\
& -\sqrt{\varphi\left(\frac{u_{2}\left(a_{i}\right)}{\sqrt{\sum_{i=1}^{m}\left(u_{2}\left(a_{i}\right)\right)^{2}}}\right)^{2}+(1-\varphi)\left(\frac{r_{2}\left(a_{i}\right)}{m(m+1) / 2}\right)^{2}}+(7) \\
& +\sqrt{\varphi\left(\frac{u_{3}\left(a_{i}\right)}{\sqrt{\sum_{i=1}^{m}\left(u_{3}\left(a_{i}\right)\right)^{2}}}\right)^{2}+(1-\varphi)\left(\frac{m-r_{3}\left(a_{i}\right)+1}{m(m+1) / 2}\right)^{2}}
\end{aligned}
$$

where the parameter $\varphi$ is used to measure the relative importance of subordinate normalized utility values and subordinate ranks. In general, it can be set as 0.5 .

\section{A Novel Distance Measure of HFLTSs: Two-way Test Distance Measure}

Distance and similarity measures are commonly used tools to measure the degrees of deviation and closeness of two objects. They are also important components of many decisionmaking methods. Assuming that $H_{S}^{1}$ and $H_{S}^{2}$ are two HFLEs on an LTS $S=\left\{s_{\alpha} \mid \alpha=0,1, \cdots, \tau\right\}$, the distance between $H_{S}^{1}$ and $H_{S}^{2}, d\left(H_{S}^{1}, H_{S}^{2}\right)$, satisfies the following conditions (Liao et al., 2014): (1) $0 \leq d\left(H_{S}^{1}, H_{S}^{2}\right) \leq 1$; (2) $d\left(H_{S}^{1}, H_{S}^{2}\right)=0$, if and only if $H_{S}^{1}=H_{S}^{2} ;(3) d\left(H_{S}^{1}, H_{S}^{2}\right)=d\left(H_{S}^{2}, H_{S}^{1}\right)$; (4) $d\left(H_{S}^{1}, H_{S}^{2}\right)+d\left(H_{S}^{2}, H_{S}^{3}\right)>d\left(H_{S}^{1}, H_{S}^{3}\right)$. Liao et al. (2014) studied the Euclidean distance measure, Hamming distance measure, Hausdorff distance measure and their weighted form in the HFL environment. Afterwards, Liao \& Xu (2015) further proposed distance and similarity measures of HFLEs based on the cosine distance. In actual operations, different HFLEs usually have different numbers of linguistic terms. In this case, most existing methods added the maximum or minimum linguistic term to the shorter HFLE according to the risk preference of experts to perform 
operations (Zhu et al., 2012). However, this method may be contrary to the original perceptions of decision-makers. For example, for two HFLEs $H_{S}^{1}=\left\{s_{3}, \mathrm{~S}_{4}, \mathrm{~S}_{5}\right\}$ and $H_{S}^{2}=\left\{s_{2}, \mathrm{~S}_{3}\right\}$, if add a linguistic term to $H_{S}^{2}$ and change it to $H_{S}^{2}$ $=\left\{s_{2}, s_{2}, s_{3}\right\}$. or $H_{S}^{2}=\left\{s_{2}, S_{3}, s_{3}\right\}$, the evaluation information contained in $H_{S}^{2}$ was changed.

Wilcoxon test, as a statistical method, has been used to test the difference between groups of sample data (Gehan, 1965). To solve the limitation of existing distance measures of HFLEs, inspired by the idea of Wilcoxon test, a new method called the two-way test distance measure is developed to calculate the distances between HFLEs. The detailed calculation steps are as follows:

Step 1 - Construct an ordered comparison set, which involves two cases:

Case 1. Unobvious dominance. For two HFLEs $H_{S}^{1}=\left\{s_{\mathrm{t}_{1}}^{1} \mid t_{1}=\alpha, \ldots, \beta\right\}\left(0 \leq \alpha \leq t_{1} \leq \beta\right.$ $\leq \tau)$ and $H_{S}^{2}=\left\{s_{t_{2}}^{2} \mid t_{2}=\delta, \ldots, \gamma\right\}\left(0 \leq \delta \leq t_{1} \leq\right.$ $\gamma \leq \tau)$ on the $\operatorname{LTS}^{2} S=\left\{s_{\alpha} \mid \alpha=0,1, \ldots, \tau\right\}$, the dominance relation between them is unobvious. In this case, rank the elements in $H_{S}^{1}$ and $H_{S}^{2}$ according to their semantics from inferior to superior, and then form an ordered comparison set as: $T\left(H_{S}^{12}\right)=H_{S}^{1} \cup H_{S}^{2}=\left\{\min \left\{s_{\alpha}^{1}, s_{\delta}^{2}\right\}, \ldots\right.$, $\left.\max \left\{s_{\beta}^{1}, s_{\gamma}^{2}\right\}\right\}$.

Case 2. Absolute dominance. For two HFLEs $H_{S}^{1}=\left\{s_{\mathrm{t}_{1}}{ }_{1} \mid t_{1}=\alpha, \ldots, \beta\right\}\left(0 \leq \alpha \leq t_{1} \leq \beta\right.$ $\leq \tau)$ and $H_{S}^{2}=\left\{s_{t_{1}}^{2} \mid t_{2}=\delta, \ldots, \gamma\right\}\left(0 \leq \delta \leq t_{1}\right.$ $\leq \gamma \leq \tau)$ on the LTS $S=\left\{s_{\alpha} \mid \alpha=0,1, \ldots, \tau\right\}$ with $\beta<\delta, H_{S}^{2}$ holds an absolute dominate position. In this case, add $(\delta-\beta-1)$ elements together with the elements in $H_{S}^{1}$ and $H_{S}^{2}$ to form an ordered comparison set as: $T\left(H_{S}^{12}\right)=\left\{s_{\alpha}^{1}, \cdots\right.$, $\left.s_{\beta}^{1}, s_{\beta+1}^{0}, \cdots, s_{\delta-1}^{0}, s_{\delta}^{2}, \cdots, s_{\gamma}^{2}\right\}$.

Step 2 - For the ordered comparison set, rank all the linguistic terms in ascending order and then get the rank value $t_{D}$ of each linguistic term. For the $t_{D}$ th smallest linguistic term in the ordered comparison set, its corresponding dominance test value $\sigma^{+}=t_{D}$. If the $t_{D}$ th and $\left(t_{D}+1\right)$ th linguistic terms in the ordered comparison set are the same, then their corresponding dominance test values $\sigma^{+}=t_{D}+\frac{1}{2}$. Similarly, rank all the linguistic terms in descending order and then get the rank value $t_{I}$ of each linguistic term in the ordered comparison set. For the $t_{l}$ th largest linguistic term in the ordered comparison set, its corresponding inferior test value is $\sigma^{-}=t_{I}$. If the $t_{I}$ th and $\left(t_{I-1}\right)$ th linguistic terms in the ordered comparison set have the same semantics, their corresponding inferior test values are $\sigma^{-}=t_{I}-\frac{1}{2}$. Then, the two-way test distance between the HFLEs $H_{S}^{1}$ and $H_{S}^{2}$ is defined as:

$d\left(H_{S}^{1}, H_{S}^{2}\right)=\left|\frac{\sum_{t_{1}=\alpha}^{\beta} \sigma_{s_{t_{1}}}^{+}}{\sum_{t_{1}=\alpha}^{\beta} \sigma_{s_{t_{1}}}^{+}+\sum_{t_{1}=\alpha}^{\beta} \sigma_{s_{t_{1}}}^{-}}-\frac{\sum_{t_{2}=\delta}^{\gamma} \sigma_{s_{t_{2}}}^{+}}{\sum_{t_{2}=\delta}^{\gamma} \sigma_{s_{t_{2}}}^{+}+\sum_{t_{2}=\delta}^{\gamma} \sigma_{s_{t_{2}}}^{-}}\right|$

where $\sum_{t_{1}=\alpha}^{\beta} \sigma_{s_{1}}^{+}$and $\sum_{t_{1}=\alpha}^{\beta} \sigma_{s_{1}}^{-}$respectively refer to the dominance and inferior test values of all the linguistic terms in $H_{S}^{1}$, while $\sum_{t_{2}=\delta}^{\gamma} \sigma_{s t_{2}}^{+}$and $\sum_{t_{2}=\delta}^{\gamma} \sigma_{s t_{2}}^{-}$and respectively refer to the dominance and inferior test values of all the linguistic terms in $H_{S}^{2}$.

Example 1. Given an LTS $S=\left\{s_{0}, s_{1}, \ldots, S_{6}\right\}$, if there are two HFLEs $H_{S}^{1}=\left\{s_{2}, s_{3}, s_{4}\right\}$ and $H_{S}^{2}=\left\{s_{2}, S_{3}\right\}$, the ordered comparison set consists of their linguistic terms is determined as $T\left(H_{S}^{12}\right)$ $=H_{S}^{1} \cup H_{S}^{2}=\left\{s_{2}, s_{2}, s_{3}, s_{3}, s_{4}\right\}$. The dominance test values are $\sigma_{s_{2}}^{+}=1.5, \sigma_{s_{3}}^{+}=3.5, \sigma_{s_{4}}^{+}=5$, and inferior test values $\sigma_{s_{2}}^{-}=4.5, \sigma_{s_{3}}^{-}=2.5$, $\sigma_{s_{4}}^{-}=1$. Then, the two-way test distance is $d\left(H_{S}^{1}, H_{S}^{2}\right)=\left|\frac{10}{10+8}-\frac{5}{5+7}\right|=0.1389$.

Example 2. Given an LTS $S=\left\{s_{0}, s_{1}, \ldots, s_{6}\right\}$, for two HFLEs $H_{S}^{1}=\left\{s_{3}\right\}, H_{S}^{2}=\left\{s_{5}, s_{6}\right\}$, the ordered comparison set consists of their linguistic terms is $T\left(H_{S}^{12}\right)=\left\{s_{3}, s_{4}, s_{5}, s_{6}\right\}$. The dominance test value are $\sigma_{s_{3}}^{+}=1, \sigma_{s_{5}}^{+}=3$ and $\sigma_{s_{6}}^{+}=4$. The inferior test values are $\sigma_{s_{3}}^{-}=4$, $\sigma_{s_{5}}^{-}=2$ and $\sigma_{s_{6}}^{-}=1$. The two-way test distance is $d\left(H_{S}^{1}, H_{S}^{2}\right)=\left|\frac{1}{1+4}-\frac{7}{7+3}\right|=0.5$.

Theorem 1: For the proposed two-way test distance measure, it satisfies:

(1) $0 \leq d\left(H_{S}^{1}, H_{S}^{2}\right) \leq 1$;

(2) $d\left(H_{S}^{1}, H_{S}^{2}\right)=0$, if and only if $H_{S}^{1}=H_{S}^{2}$;

(3) $d\left(H_{S}^{1}, H_{S}^{2}\right)=d\left(H_{S}^{2}, H_{S}^{1}\right)$;

(4) $d\left(H_{S}^{1}, H_{S}^{2}\right)+d\left(H_{S}^{2}, H_{S}^{3}\right)>d\left(H_{S}^{1}, H_{S}^{3}\right)$.

The proof of the fourth theorem of Theorem 1 is given in the appendix.

\section{Hesitant Fuzzy Linguistic MCDM Method with the Improved SWARA and DNMA Methods}

In this section, an integrated MCDM method which combines the improved SWARA and DNMA methods under the HFL environment is proposed. The improved SWARA method is used to determine the weights of criteria. The proposed two-way test distance measure of HFLEs is applied in the DNMA method to obtain the alternative ranking. 


\begin{tabular}{|c|c|c|c|c|}
\hline $\begin{array}{ll}\text { Tab. 2: } & \begin{array}{l}\text { Use the original SV } \\
\text { resolution }\end{array}\end{array}$ & A method to calc & late the cri & ria weights 0 & dispute \\
\hline Criteria & $\begin{array}{c}\text { Comparative } \\
\text { importance of the } \\
\text { average value } \xi_{j}\end{array}$ & $\begin{array}{c}\text { Coefficient } \\
K_{j}\end{array}$ & $\begin{array}{c}\text { Recalculate } \\
\text { weight } W_{j}\end{array}$ & $\begin{array}{l}\text { Normalized } \\
\text { Weight } q_{j}\end{array}$ \\
\hline $\begin{array}{l}\text { Expedition of dispute resolution } \\
\left(\hat{C}_{1}\right)\end{array}$ & - & 1 & 1 & 0.22 \\
\hline Price of dispute resolution $\left(\hat{C}_{2}\right)$ & 0.15 & 1.15 & 0.87 & 0.19 \\
\hline Possibility to appeal $\left(\hat{C}_{3}\right)$ & 0.04 & 1.04 & 0.84 & 0.18 \\
\hline Assurance of confidentiality $\left(\hat{C}_{4}\right)$ & 0.29 & 1.29 & 0.65 & 0.14 \\
\hline $\begin{array}{l}\text { Authority of person solving the } \\
\text { dispute }\left(\hat{c}_{5}\right)\end{array}$ & 0.02 & 1.02 & 0.64 & 0.14 \\
\hline Legal advice $\left(\hat{c}_{6}\right)$ & 0.04 & 1.04 & 0.61 & 0.13 \\
\hline
\end{tabular}

Source: Keršulienè et al. (2010)

\subsection{Improved SWARA Method}

The SWARA method can synthesize expert opinions and reflect the importance differences of criteria. However, in Tab. 2, the importance of criterion $\hat{c}_{4}$ over criterion $\hat{c}_{5}$ is $\xi_{5}=0.02$, but when observing the calculated results, the weights of $\hat{c}_{4}$ and $\hat{c}_{5}$ are equal. In other words, the importance difference between criteria may not be reflected in the calculation results.

To avoid the above limitations, some improvements are made on the basis of retaining the core idea of the original SWARA method. Firstly, adjust the calculation process of $K_{j}$ using the difference between the importance of criterion $\hat{c}_{j}$ and the previous criterion $\hat{c}_{j-1}$. Then, adjust the weight $W_{j}$ of the criterion $\hat{c}_{j}$ with the adjustment coefficient $K_{j}$, and get the weight $q_{j}$ of the criterion after standardization. The calculation steps of the improved method are as follows:

Experts rank criteria $c_{1}, c_{2}, \ldots, c_{n}$ according to their importance. After ranking, the criteria set is $\hat{C}=\left\{\hat{c}_{j} \mid j=1,2, \ldots, n\right\}$. The criteria are compared in order from big to small. $\xi_{j}$ is used to indicate how much more important $\hat{c}_{j-1}$ is than $\hat{c}_{j}$. Then, the adjustment coefficient $K_{j}$ of criterion $\hat{c}_{j}$ related to the previous criterion is calculated according to the important difference of criteria:

$$
K_{j}=\left\{\begin{array}{c}
1, j=1 \\
1-\xi_{j}, j>1
\end{array}\right.
$$

\begin{tabular}{|c|c|c|c|c|c|}
\hline $\begin{array}{l}\text { Use the improv } \\
\text { resolution }\end{array}$ & Ied SWARA metho & od to calcu & the crit & veigh & dispute \\
\hline Criteria & $\begin{array}{c}\text { Comparative } \\
\text { importance of the } \\
\text { average value } \xi_{j}\end{array}$ & $\begin{array}{c}\text { Adjustment } \\
\text { coefficient } \\
K_{j}\end{array}$ & $\begin{array}{c}\text { Adjusted } \\
\text { weight } \\
W_{j}\end{array}$ & $\begin{array}{c}\text { Final } \\
\text { weight } \\
q_{j}\end{array}$ & $\begin{array}{c}\text { Results of } \\
\text { the original } \\
\text { method }\end{array}$ \\
\hline $\begin{array}{l}\text { Expedition of dispute } \\
\text { resolution }\left(\hat{c}_{1}\right)\end{array}$ & - & 1 & 1 & 0.2295 & 0.22 \\
\hline $\begin{array}{l}\text { Price of dispute resolution } \\
\left(\hat{C}_{2}\right)\end{array}$ & 0.15 & 0.85 & 0.85 & 0.195 & 0.19 \\
\hline Possibility to appeal $\left(\hat{c}_{3}\right)$ & 0.04 & 0.96 & 0.816 & 0.1872 & 0.18 \\
\hline $\begin{array}{l}\text { Assurance of confidentiality } \\
\left(\hat{C}_{4}\right)\end{array}$ & 0.29 & 0.71 & 0.5794 & 0.1329 & 0.14 \\
\hline $\begin{array}{l}\text { Authority of person solving } \\
\text { the dispute }\left(\hat{c}_{5}\right)\end{array}$ & 0.02 & 0.98 & 0.5678 & 0.1303 & 0.14 \\
\hline Legal advice $\left(\hat{C}_{6}\right)$ & 0.04 & 0.96 & 0.545 & 0.1251 & 0.13 \\
\hline
\end{tabular}


According to the adjustment coefficient, the adjusted weight is obtained as:

$$
W_{j}=\left\{\begin{array}{c}
1, j=1 \\
W_{j-1} K_{j}, j>1
\end{array}\right.
$$

After standardization, the criteria weights are obtained as:

$$
q_{j}=W_{j} / \sum W_{j}, \text { for } j=1,2, \cdots, n
$$

Example 3. For the data in Tab. 2, the results calculated by the improved method are shown in Tab. 3.

From Example 3, it can be find that in the improved SWARA method, when calculating the adjustment coefficient $K_{j}$, it is consistent with the meaning of $\xi_{j}$ as each criterion is connected with the former criterion, and the calculated value of $K_{j}$ conforms to the ranking rule of criteria importance. Taking $\hat{c}_{4}$ and $\hat{c}_{5}$ as an example, even if the importance difference between them is small, the gap can be reflected in the results of criteria weights.

\subsection{Integrated Hesitant Fuzzy Linguistic MCDM Method}

In the HFL environment, an integrated MCDM model with the improved SWARA and DNMA methods is developed considering the proposed two-way test distance measure. The steps of this method are as follows:

Step 1 - The criteria $c_{j}(j=1,2, \ldots, n)$ are determined according to the practical MCDM problem. Experts give the ranking of these criteria. Then, the criteria are sorted in descending order according to their importance, and the new ranking are $\hat{c}_{j}(j=1,2, \ldots, n)$. Set up appropriate linguistic term set to express the experts' evaluation values of the importance of criteria. Using the score function of HFLEs given as formula 1, convert the hesitant fuzzy linguistic evaluation values into crisp numbers, and then use the improved SWARA method to calculate the weights of criteria through formulas 9-11.

Step 2 - Ask the experts $e_{k}(K=1,2, \ldots, G)$ to furnish the evaluation matrices $D^{K}(K=1,2$, $\ldots, G)$ in which the element $h_{S_{i j}}^{k}$ represents the judgment value of alternative $a_{i}(i=1,2, \ldots, m)$ under criterion $c_{j}(i=1,2, \ldots, n)$ given by expert $e_{k}$.

Step 3 - For the elements in each decision matrix, formula 1 is used to convert the HFLEs to crisp values. The optimal value $r_{j}^{k}$ of $j$ th column is found according to the characteristics of criteria. The linear normalized value and vector normalized values are then calculated by formulas 2,3 and 8 . Multiply each linear normalized matrix and vector normalized matrix by the corresponding weight of each expert, then add them together, the total linear normalization matrix and vector normalization matrix are obtained.

Step 4 - Use formulas 4,5 and 6 to calculate the aggregate values based on CCM, UCM and ICM models respectively. Based on the outputs of the three models, the utility values of alternatives are obtained by formula 7 , and the ranking of alternatives is deduced.

In the above procedure, Steps 1 and 2 are used to determine criteria weights by the improved HFL-SWARA method. This method is suitable for solving the problem with a large number of criteria. In Steps 3 and 4, use the HFL-DNMA method to get the utility values of alternatives. The proposed two-way test distance measure is applied to the HFL-DNMA method, which can calculate the distances between HFLEs with unequal length without changing the experts' original information.

\section{Case Study: Sustainable Construction Supplier Selection}

This section takes sustainable building supplier selection as an example to illustrate the applicability of the proposed method.

\subsection{Case Background}

At present, the shortage of resources and environmental pollution in the world restrict the development of society. Under this background, the significance of green development is deeply rooted in the hearts of people all over the world. Pollution of building materials is harmful to human body. Poor materials can release harmful substances such as formaldehyde and volatile organic compounds (VOC), which can cause cancer, leukemia, reproductive diseases, asphyxia and other health problems, and even seriously endanger our lives. Many industries introduced green supply chain to seek a greener and longer-term development. Facing the complex and changeable market environment, the competition among construction enterprises is more and more intense. The competition has gradually transited to the supply chain level, 
and suppliers become an important extension of the core value chain of enterprises. Enterprises should not take cost and profit as the sole orientation. Optimizing supply chain and adopting high-quality cooperative suppliers are the key to enhance competitiveness and achieve sustainable development for a company in modern society.

A construction company in Southwest China has four alternative building material suppliers $A=\left\{a_{1}, a_{2}, a_{3}, a_{4}\right\}$. Four experts $E=\left\{e_{1}, e_{2}\right.$, $\left.e_{3}, e_{4}\right\}$ are invited to evaluate the alternatives. They are an economist, a material evaluator, an environmental expert and a market evaluation organization personnel. The weights of the experts are $W_{E}=(0.3,0.3,0.2,0.2)^{T}$. Based on experts' opinions and relevant literature, the specific criteria for construction suppliers are identified as shown in Tab. 4.

\subsection{Apply the Proposed Method to Select Sustainable Construction Suppliers}

The sustainable construction supplier selection problem is solved by the MCDM method proposed in Section 4.2. The calculation steps are as follows:

Step 1 - The importance rankings of criteria and sub-criteria given by experts are as follows: $c_{1}>c_{2}, c_{12}>c_{11}>c_{15}>c_{13}>c_{14}$, and $c_{23}>$ $c_{22}>c_{21}$. Then, set up an LTS such that experts

\section{Tab. 4: Evaluation criteria for construction suppliers}

\begin{tabular}{|c|c|c|c|}
\hline Dimensions & Criteria & Explanation & Type \\
\hline \multirow{5}{*}{ Product level } & Price & $\begin{array}{l}\text { The price was set by the supplier when } \\
\text { purchasing a product. }\end{array}$ & Cost \\
\hline & Performance and quality fit & $\begin{array}{l}\text { The degree to which the function and } \\
\text { quality of a product meet the company's } \\
\text { building needs. }\end{array}$ & Benefit \\
\hline & Logistics flexibility & $\begin{array}{l}\text { The ability to respond to the needs of } \\
\text { construction companies and deliver on time. }\end{array}$ & Benefit \\
\hline & Variety flexibility & $\begin{array}{l}\text { The ability to meet the diverse needs of } \\
\text { construction companies. }\end{array}$ & Benefit \\
\hline & Green degree of products & $\begin{array}{l}\text { Whether the product is green design, } \\
\text { energy saving and consumption reduction. }\end{array}$ & Benefit \\
\hline \multirow{3}{*}{ Entity level } & Development potential & $\begin{array}{l}\text { The material should have good corrosion } \\
\text { resistance. }\end{array}$ & Benefit \\
\hline & Corporate reputation & $\begin{array}{l}\text { The material should have good fire } \\
\text { resistance. }\end{array}$ & Benefit \\
\hline & Information sharing degree & Service life of the material. & Benefit \\
\hline
\end{tabular}

\section{Tab. 5: $\quad$ Relative importance of basic criteria}

\begin{tabular}{c|c|c} 
& $c_{1}$ & $c_{2}$ \\
\hline$e_{1}$ & - & $\left\{s_{2}, s_{3}, s_{4}\right\}$ \\
\hline$e_{2}$ & - & $\left\{s_{2}\right\}$ \\
\hline$e_{3}$ & - & $\left\{s_{2}, s_{3}, s_{4}\right\}$ \\
\hline$e_{4}$ & - & $\left\{s_{0}, s_{1}\right\}$ \\
\hline$\xi_{j}$ & - & 0.5500
\end{tabular}


Tab. 6: Relative importance of the criteria for the product layer

\begin{tabular}{c|c|c|c|c|c} 
& $c_{12}$ & $c_{11}$ & $c_{15}$ & $c_{13}$ & $c_{14}$ \\
\hline$e_{1}$ & - & $\left\{s_{0}, s_{1}\right\}$ & $\left\{s_{0}, s_{1}, s_{2}\right\}$ & $\left\{s_{1}, s_{2}\right\}$ & $\left\{s_{0}, s_{1}\right\}$ \\
\hline$e_{2}$ & - & $\left\{s_{1}\right\}$ & $\left\{s_{0}, s_{1}\right\}$ & $\left\{s_{3}\right\}$ & $\left\{s_{0}, s_{1}, s_{2}\right\}$ \\
\hline$e_{3}$ & - & $\left\{s_{0}, s_{1}\right\}$ & $\left\{s_{1}\right\}$ & $\left\{s_{1}, s_{2}, s_{3}\right\}$ & $\left\{s_{0}, s_{1}\right\}$ \\
\hline$e_{4}$ & - & $\left\{s_{0}, s_{1}, s_{2}\right\}$ & $\left\{s_{0}, s_{1}, s_{2}\right\}$ & $\left\{s_{0}, s_{1}\right\}$ & $\left\{s_{2}, s_{3}\right\}$ \\
\hline$\xi_{j}$ & - & 0.1875 & 0.2125 & 0.4625 & 0.2625 \\
\hline
\end{tabular}

Source: own

Tab. 7: Relative importance of criteria for the entity layer

\begin{tabular}{c|c|c|c} 
& $c_{23}$ & $c_{22}$ & $c_{21}$ \\
\hline$e_{1}$ & - & $\left\{s_{0}, s_{1}\right\}$ & $\left\{s_{0}, s_{1}, s_{2}\right\}$ \\
\hline$e_{2}$ & - & $\left\{s_{1}, s_{2}\right\}$ & $\left\{s_{1}, s_{2}, s_{3}\right\}$ \\
\hline$e_{3}$ & - & $\left\{s_{1}\right\}$ & $\left\{s_{1}, s_{2}\right\}$ \\
\hline$e_{4}$ & - & $\left\{s_{0}, s_{1}, s_{2}\right\}$ & $\left\{s_{3}\right\}$ \\
\hline$\xi_{j}$ & - & 0.2500 & 0.4500 \\
\hline
\end{tabular}

Source: own

can use the given information to assess the importance of criteria.

$S=\left\{\begin{array}{l}S_{0}=\text { equal important, } s_{1}=\text { slightly less important }, \\ s_{2}=\text { very less important, } s_{3}=\text { strongly less } \\ \text { important, } s_{4}=\text { extremely less important }\end{array}\right\}$
The relative important evaluation results are collected and we can get the scores of these HFLEs by formula 1, as shown in Tabs. 5-7:

Using the improved SWARA method, the weights of criteria are calculated by formulas 9-11. The calculation results are shown in Tabs. 8-10.

\section{Tab. 8:}

Weights of basic criteria

\begin{tabular}{c|c|c|c|c} 
& $\xi_{j}$ & $K_{j}$ & $W_{j}$ & $q_{j}$ \\
\hline$c_{1}$ & - & 1 & 1 & 0.6897 \\
\hline$c_{2}$ & 0.5500 & 0.4500 & 0.4500 & 0.3103 \\
\hline
\end{tabular}

Source: own

\section{Tab. 9: Weights of criteria for the product layer}

\begin{tabular}{c|c|c|c|c} 
& $\xi_{j}$ & $K_{j}$ & $W_{j}$ & $q_{j}$ \\
\hline$c_{12}$ & - & 1 & 1 & 0.3279 \\
\hline$c_{11}$ & 0.1875 & 0.8125 & 0.8125 & 0.2664 \\
\hline$c_{15}$ & 0.2125 & 0.7875 & 0.6398 & 0.2098 \\
\hline$c_{13}$ & 0.4625 & 0.5375 & 0.3439 & 0.1128 \\
\hline$c_{14}$ & 0.2625 & 0.7375 & 0.2536 & 0.0831 \\
\hline
\end{tabular}


Tab. 10: Weights of criteria for the entity layer

\begin{tabular}{c|c|c|c|c} 
& $\xi_{j}$ & $K_{j}$ & $W_{j}$ & $q_{j}$ \\
\hline$c_{23}$ & - & 1 & 1 & 0.4624 \\
\hline$c_{22}$ & 0.25 & 0.75 & 0.75 & 0.3468 \\
\hline$c_{21}$ & 0.45 & 0.55 & 0.4125 & 0.1908 \\
\hline
\end{tabular}

Source: own

The criteria weights are calculated as $\left(w_{11}, w_{12}, w_{13}, w_{14}, w_{15}\right)^{T}=(0.1837,0.2262,0.0778$, $0.0573,0.1447)^{T}$ and $\left(\mathrm{w}_{21}, \mathrm{w}_{22}, \mathrm{w}_{23}\right)^{T}=(0.0592,0.1076,0.1435)^{T}$.

Step 2 - Set the linguistic term set as follows to evaluate the alternatives:

$S=\left\{\begin{array}{l}S_{0}=\text { extremely low }, s_{1}=\text { very low }, s_{2}=\text { a little low }, \\ s_{3}=\text { medium, } s_{4}=\text { a little high, } s_{5}=\text { very high }, \\ s_{6}=\text { extremely high }\end{array}\right\}$

The evaluation values are given by the experts as follows:

$$
\begin{aligned}
& D^{1}=\left(\begin{array}{cccccccc}
\left\{s_{3}, s_{4}\right\} & \left\{s_{4}, s_{5}\right\} & \left\{s_{3}, s_{4}\right\} & \left\{s_{2}, s_{3}\right\} & \left\{s_{2}, s_{3}, s_{4}\right\} & \left\{s_{4}, s_{5}\right\} & \left\{s_{0}, s_{1}, s_{2}\right\} & \left\{s_{4}, s_{5}, s_{6}\right\} \\
\left\{s_{5}\right\} & \left\{s_{2}, s_{3}, s_{4}\right\} & \left\{s_{4}\right\} & \left\{s_{3}, s_{4}\right\} & \left\{s_{3}\right\} & \left\{s_{1}, s_{2}\right\} & \left\{s_{3}\right\} & \left\{s_{3}, s_{4}\right\} \\
\left\{s_{1}, s_{2}, s_{3}\right\} & \left\{s_{2}, s_{3}\right\} & \left\{s_{2}, s_{3}, s_{4}\right\} & \left\{s_{3}\right\} & \left\{s_{4}, s_{5}\right\} & \left\{s_{3}, s_{4}, s_{5}\right\} & \left\{s_{3}, s_{4}\right\} & \left\{s_{2}, s_{3}, s_{4}\right\} \\
\left\{s_{2}, s_{3}\right\} & \left\{s_{3}, s_{4}\right\} & \left\{s_{1}\right\} & \left\{s_{1}, s_{2}\right\} & \left\{s_{4}\right\} & \left\{s_{5}\right\} & \left\{s_{4}\right\} & \left\{s_{1}\right\}
\end{array}\right) \\
& D^{2}=\left(\begin{array}{cccccccc}
\left\{s_{4}, s_{5}\right\} & \left\{s_{3}, s_{4}\right\} & \left\{s_{4}, s_{5}\right\} & \left\{s_{2}, s_{3}\right\} & \left\{s_{3}, s_{4}\right\} & \left\{s_{4}\right\} & \left\{s_{1}, s_{2}\right\} & \left\{s_{5}\right\} \\
\left\{s_{3}, s_{4}, s_{5}\right\} & \left\{s_{2}, s_{3}\right\} & \left\{s_{3}, s_{4}\right\} & \left\{s_{4}\right\} & \left\{s_{2}, s_{3}, s_{4}\right\} & \left\{s_{0}, s_{1}\right\} & \left\{s_{2}, s_{3}, s_{4}\right\} & \left\{s_{3}, s_{4}, s_{5}\right\} \\
\left\{s_{1}, s_{2}\right\} & \left\{s_{3}\right\} & \left\{s_{2}, s_{3}, s_{4}\right\} & \left\{s_{3}, s_{4}\right\} & \left\{s_{3}, s_{4}, s_{5}\right\} & \left\{s_{3}, s_{4}\right\} & \left\{s_{4}\right\} & \left\{s_{3}, s_{4}\right\} \\
\left\{s_{2}, s_{3}, s_{4}\right\} & \left\{s_{2}, s_{3}, s_{4}\right\} & \left\{s_{1}, s_{2}\right\} & \left\{s_{1}, s_{2}, s_{3}\right\} & \left\{s_{4}, s_{5}\right\} & \left\{s_{3}, s_{4}, s_{5}\right\} & \left\{s_{3}\right\} & \left\{s_{2}, s_{3}, s_{4}\right\}
\end{array}\right) \\
& D^{3}=\left(\begin{array}{cccccccc}
\left\{s_{5}\right\} & \left\{s_{4}, s_{5}, s_{6}\right\} & \left\{s_{3}, s_{4}, s_{5}\right\} & \left\{s_{3}\right\} & \left\{s_{3}, s_{4}\right\} & \left\{s_{4}, s_{5}\right\} & \left\{s_{0}, s_{1}, s_{2}\right\} & \left\{s_{5}, s_{6}\right\} \\
\left\{s_{4}, s_{5}, s_{6}\right\} & \left\{s_{3}, s_{4}\right\} & \left\{s_{4}\right\} & \left\{s_{4}, s_{5}\right\} & \left\{s_{2}, s_{3}, s_{4}\right\} & \left\{s_{0}, s_{1}\right\} & \left\{s_{3}\right\} & \left\{s_{3}, s_{4}, s_{5}\right\} \\
\left\{s_{2}, s_{3}, s_{4}\right\} & \left\{s_{4}, s_{5}\right\} & \left\{s_{2}, s_{3}, s_{4}\right\} & \left\{s_{4}\right\} & \left\{s_{5}\right\} & \left\{s_{4}\right\} & \left\{s_{2}, s_{3}, s_{4}\right\} & \left\{s_{2}, s_{3}\right\} \\
\left\{s_{4}\right\} & \left\{s_{2}, s_{3}\right\} & \left\{s_{1}, s_{2}, s_{3}\right\} & \left\{s_{0}, s_{1}\right\} & \left\{s_{3}, s_{4}, s_{5}\right\} & \left\{s_{5}\right\} & \left\{s_{3}, s_{4}\right\} & \left\{s_{1}\right\}
\end{array}\right) \\
& D^{4}=\left(\begin{array}{cccccccc}
\left\{s_{3}, s_{4}, s_{5}\right\} & \left\{s_{6}\right\} & \left\{s_{4}, s_{5}\right\} & \left\{s_{2}, s_{3}\right\} & \left\{s_{4}\right\} & \left\{s_{3}, s_{4}, s_{5}\right\} & \left\{s_{4}, s_{5}\right\} & \left\{s_{4}, s_{5}, s_{6}\right\} \\
\left\{s_{5}, s_{6}\right\} & \left\{s_{2}, s_{3}, s_{4}\right\} & \left\{s_{3}, s_{4}, s_{5}\right\} & \left\{s_{5}\right\} & \left\{s_{3}, s_{4}, s_{5}\right\} & \left\{s_{2}\right\} & \left\{s_{2}, s_{3}, s_{4}\right\} & \left\{s_{4}, s_{5}\right\} \\
\left\{s_{3}\right\} & \left\{s_{3}, s_{4}, s_{5}\right\} & \left\{s_{3}, s_{4}\right\} & \left\{s_{2}, s_{3}, s_{4}\right\} & \left\{s_{4}, s_{5}\right\} & \left\{s_{3}, s_{4}\right\} & \left\{s_{4}, s_{5}\right\} & \left\{s_{2}, s_{3}\right\} \\
\left\{s_{3}, s_{4}, s_{5}\right\} & \left\{s_{2}, s_{3}\right\} & \left\{s_{1}, s_{2}, s_{3}\right\} & \left\{s_{1}\right\} & \left\{s_{3}, s_{4}\right\} & \left\{s_{3}, s_{4}, s_{5}\right\} & \left\{s_{4}\right\} & \left\{s_{1}, s_{2}, s_{3}\right\}
\end{array}\right)
\end{aligned}
$$

Step 3 - Formula 1 is used to get the evaluation matrices with crisp values:

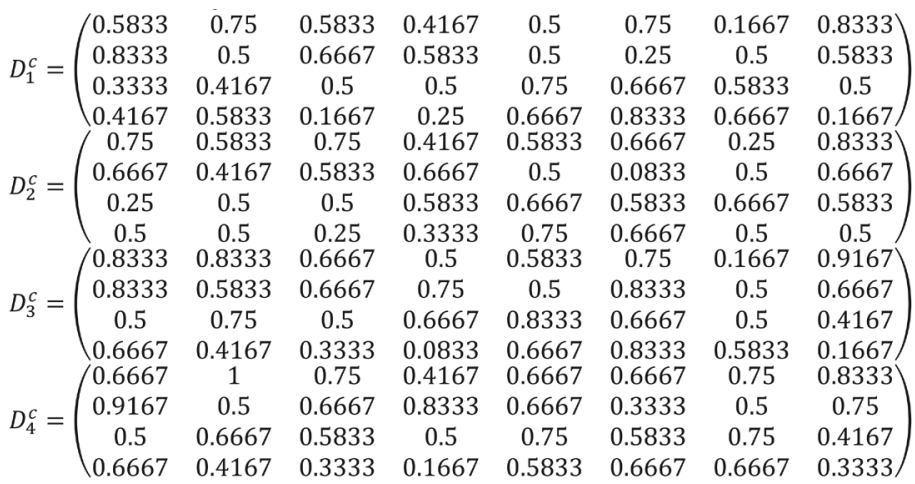




\section{Business Administration and Management}

The optimum value of each criterion is determined, which is used in the calculation of the linear normalization and vector normalization. Using formulas 2 and 8 to calculate the linear normalized values, the linear normalized decision matrices are obtained as:

$$
\begin{aligned}
& \widehat{D}_{1}=\left(\begin{array}{llllllll}
0.1616 & 1.0000 & 0.8188 & 0.3120 & 0.0000 & 0.5000 & 0.3142 & 1.0000 \\
0.0000 & 0.1320 & 1.0000 & 1.0000 & 0.1054 & 0.0000 & 0.0000 & 0.3952 \\
1.0000 & 0.0000 & 0.5555 & 0.0625 & 1.0000 & 0.2888 & 0.6786 & 0.3364 \\
0.7222 & 0.2500 & 0.0000 & 0.0000 & 0.5527 & 1.0000 & 1.0000 & 0.0000
\end{array}\right) \\
& \begin{array}{lllllllll}
0.0000 & 1.0000 & 1.0000 & 0.0625 & 0.1359 & 1.0000 & 0.0000 & 1.0000
\end{array} \\
& \widehat{D}_{2}=\left(\begin{array}{lllllllll}
0.1666 & 0.0000 & 0.4000 & 1.0000 & 0.0000 & 0.0000 & 0.4666 & 0.2888 \\
1.0000 & 0.3750 & 0.3056 & 0.5313 & 0.5999 & 0.6786 & 1.0000 & 0.0000 \\
0.3056 & 0.4907 & 0.0000 & 0.0000 & 1.0000 & 1.0000 & 0.3332 & 0.2000
\end{array}\right)
\end{aligned}
$$

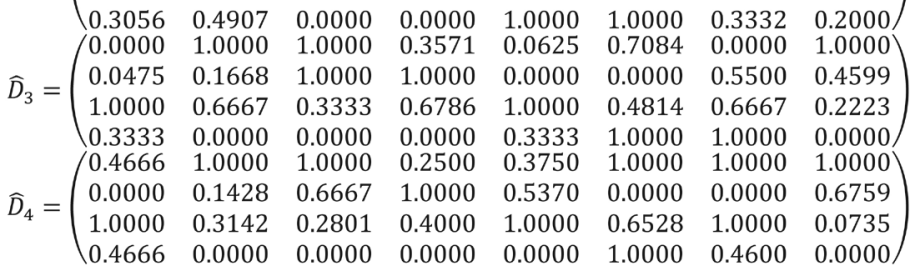

Using formulas 3 and 8, compute the vector normalized decision matrices as:

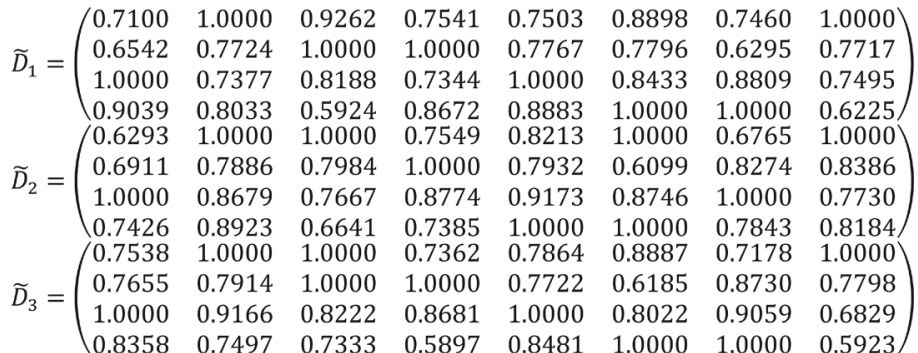

$$
\begin{aligned}
& \widetilde{D}_{4}=\left(\begin{array}{llllllll}
0.8402 & 1.0000 & 1.0000 & 0.6938 & 0.8901 & 1.0000 & 1.0000 & 1.0000 \\
0.7004 & 0.7048 & 0.9114 & 1.0000 & 0.9186 & 0.7385 & 0.7932 & 0.9129 \\
1.0000 & 0.7638 & 0.8087 & 0.7550 & 1.0000 & 0.9092 & 1.0000 & 0.7509 \\
0.8402 & 0.6556 & 0.7342 & 0.5917 & 0.8241 & 1.0000 & 0.8883 & 0.7312
\end{array}\right)
\end{aligned}
$$

Considering the weights of experts, the total linear normalization matrix and vector normalization matrix are obtained as:

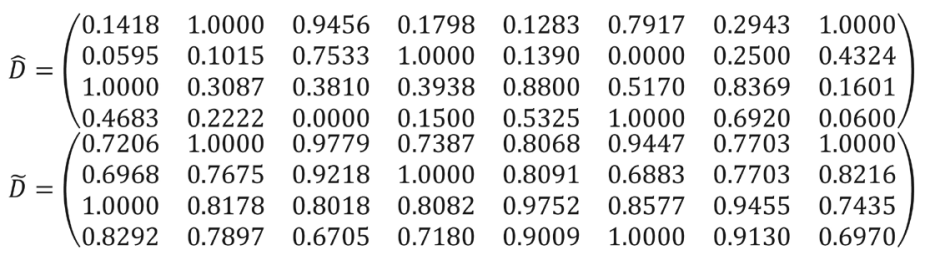

Step 4-Formulas 4, 5 and 6 are used to calculate the utility values of alternatives corresponding to the CCM, UCM and ICM, respectively. The comprehensive utility value of each alternative is obtained by formula 7 . The calculation results are shown in Tab. 11. 


\begin{tabular}{|c|c|c|c|c|}
\hline Tab. 11: Scores of alter & es basec & e aggre & perators & \\
\hline & $a_{1}$ & $a_{2}$ & $a_{3}$ & $a_{4}$ \\
\hline $\mathrm{CCM}$ & 0.5767 & 0.2589 & 0.5767 & 0.3556 \\
\hline UCM & 0.1261 & 0.1844 & 0.3856 & 0.2316 \\
\hline ICM & 0.8678 & 0.7854 & 0.8727 & 0.8069 \\
\hline Comprehensive utility value & 0.6655 & 0.1481 & 0.4309 & 0.3090 \\
\hline
\end{tabular}

Source: own

According to the comprehensive utility values, we can get the order of alternatives as $a_{1}>a_{3}>a_{4}>a_{2}$.

Based on the results, considering the criteria at the product level and the company level, the comprehensive scores of the four optional suppliers are ranked as: $a_{1}>a_{3}>a_{4}>a_{2}$. Therefore, the construction company should select $a_{1}$ to achieve the enterprise goals.

\subsection{Sensitivity Analysis}

To verify the influence of parameter changes on model outputs, sensitivity analysis is conducted. $\varphi$ is the coefficient to highlight the importance between the subordinate utility values and subordinate ranks (Liao \& Wu, 2020). Fig. 1 demonstrates how the evaluation results changes when $\varphi$ changes.

\section{Fig. 1: Sensitivity analysis based on parameter $\varphi$}

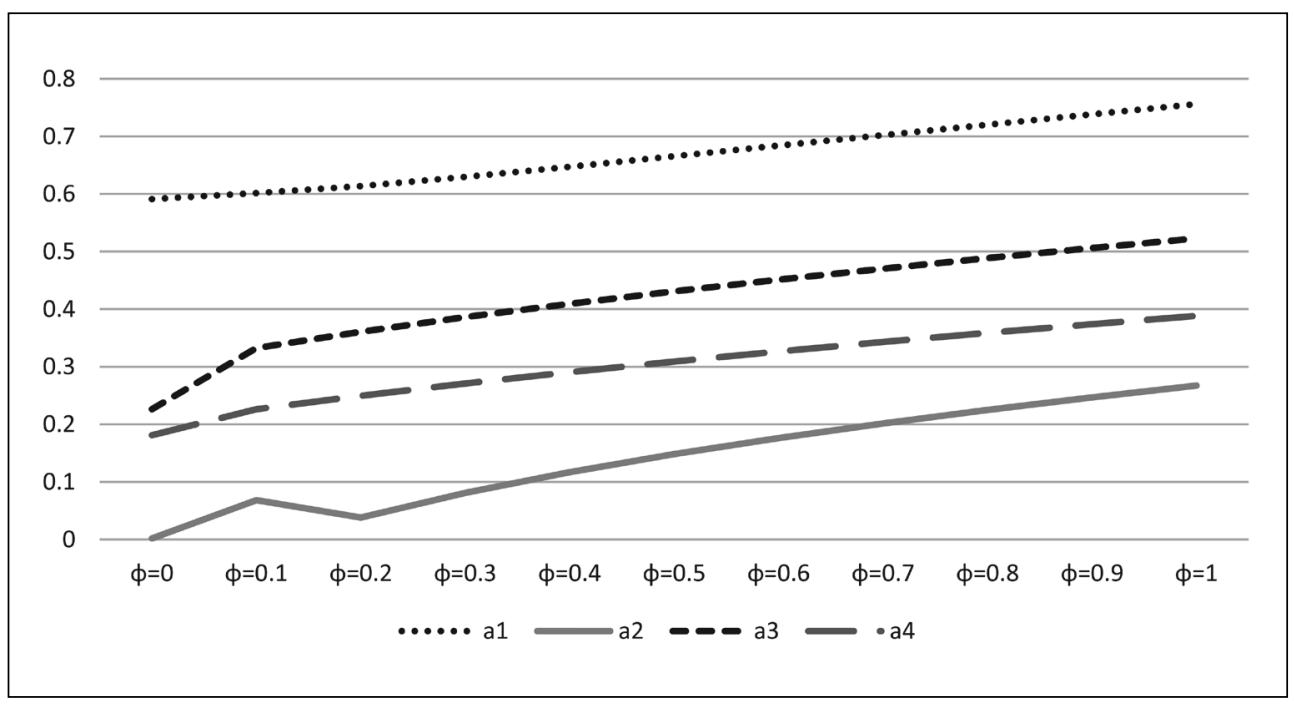

Source: own

As shown in Fig. 1, when the parameter changes from 0 to 1 , the utility values of the schemes change correspondingly, but the ranking results remain unchanged. Therefore, the final evaluation result is stable and $a_{1}$ is the best supplier for this construction company.

\subsection{Comparative Analysis}

To verify the validity of the proposed HFLMCDM method, we use the HFL-WASPAS method (Zavadskas et al., 2012; Ren et al., 2019) and the HFL-TOPSIS method (Liao et al., $2015 b)$ to solve this case. 


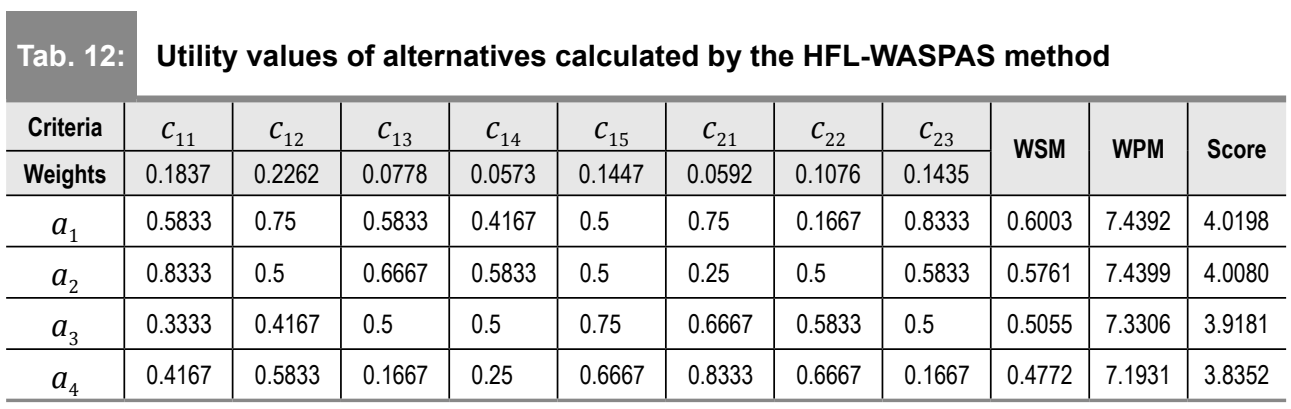

Source: own

\section{a) HFL-WASPAS}

The calculation process using the HFLWASPAS method is shown in Tab. 12.

Using the WASPAS method, combined with Weighted Sum Model (WSM) and Weighted Product Model (WPM), the comprehensive utility value was calculated. The final scores of the alternatives are: $4.0198,4.0080,3.9181$, and 3.8352 . Then the alternatives are ranked as $a_{1}>a_{2}>a_{3}>a_{4}$. Therefore, the construction company should select $a_{1}$ a as the optimal supplier. b) HFL-TOPSIS

Since the distance measure is also used in the TOPSIS method, the proposed two-way test distance measure is applied in the calculation process.

Firstly, calculate the distances between the evaluation values and the positive ideal solution under each criterion. The results are listed in Tab. 12.

Calculate the distances between the evaluation values and the negative ideal solution under each criterion. The results are shown in Tab. 13:

\section{Tab. 13: Distances between the alternatives and the positive ideal solution}

\begin{tabular}{c|c|c|c|c|c|c|c|c} 
Alternative & $c_{11}$ & $c_{12}$ & $c_{13}$ & $c_{14}$ & $c_{15}$ & $c_{21}$ & $c_{22}$ & $c_{23}$ \\
\hline$a_{1}$ & 0.4091 & 0.0000 & 0.0326 & 0.3917 & 0.3283 & 0.0938 & 0.3533 & 0.0000 \\
\hline$a_{2}$ & 0.4512 & 0.3636 & 0.1178 & 0.0000 & 0.3244 & 0.4961 & 0.3619 & 0.2814 \\
\hline$a_{3}$ & 0.0000 & 0.2840 & 0.2975 & 0.2863 & 0.0417 & 0.2307 & 0.0840 & 0.4062 \\
\hline$a_{4}$ & 0.2525 & 0.3358 & 0.4933 & 0.4263 & 0.1696 & 0.0000 & 0.1375 & 0.4765 \\
\hline
\end{tabular}

\section{Tab. 14: Distances between the alternatives and the negative ideal solution}

\begin{tabular}{c|c|c|c|c|c|c|c|c} 
Alternative & $c_{11}$ & $c_{12}$ & $c_{13}$ & $c_{14}$ & $c_{15}$ & $c_{21}$ & $c_{22}$ & $c_{23}$ \\
\hline$a_{1}$ & 0.4800 & 0.2029 & 0.3534 & 0.4225 & 0.4158 & 0.4167 & 0.3519 & 0.2584 \\
\hline$a_{2}$ & 0.0417 & 0.1295 & 0.4787 & 0.4900 & 0.0278 & 0.0000 & 0.1963 & 0.3388 \\
\hline$a_{3}$ & 0.1792 & 0.4100 & 0.4633 & 0.3667 & 0.1070 & 0.5193 & 0.1894 & 0.4990 \\
\hline$a_{4}$ & 0.3727 & 0.1917 & 0.0000 & 0.0000 & 0.2375 & 0.4961 & 0.4375 & 0.1042 \\
\hline \multicolumn{1}{|c|}{} & \multicolumn{1}{c}{ Source: own }
\end{tabular}




\section{Fig. 2: Results calculated by HFL-DNMAIHFL-WASPASIHFL-TOPSIS method}

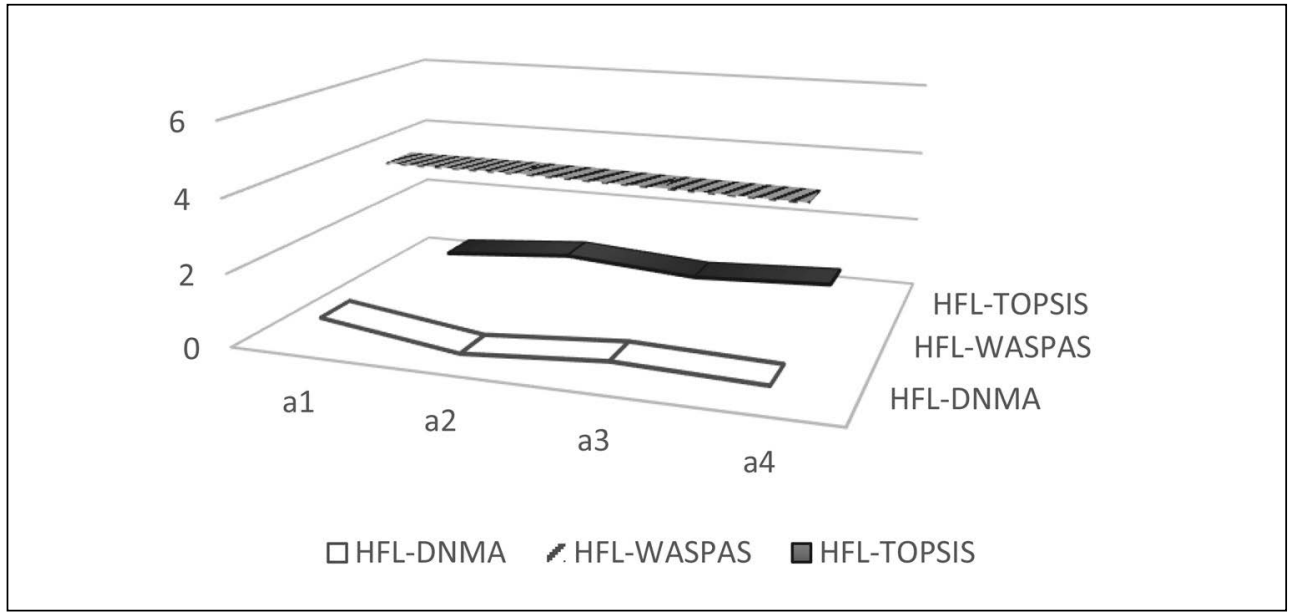

Source: own

The criteria weights are used to aggregate the distance values from each alternative to the positive and negative ideal solutions, and the evaluation reference values are calculated as $0.3558,0.6521,0.3733$ and 0.5552 . The distance between $a_{1}$ and ideal solution is the shortest, so the construction company should select $a_{1}$ a as the supplier.

Since the best alternative derived by the HFL-WASPAS method and the HFL-TOPSIS method is $a_{1}$, the validity of the proposed decision-making model is verified.

The HFL-WASPAS method does not use the two-way test distance measure in the calculation process, while the HFL-TOPSIS method and the model proposed in this paper use this distance measure in the calculation process. The comparison of the results calculated by the three methods is shown in Fig. 2. It can be seen that when the two-way test distance measure is not used, there is little difference between the calculated results of the alternatives. In some cases, it is hard to distinguish the advantages and disadvantages of alternatives. To sum up, the two-way test distance measure can retain information integrity and better reflect the differences between evaluation information.

This model uses the improved SWARA method to determine the weights of criteria, which can sensitively respond to the small differences between criteria. The method is convenient, effective and easy to operate. In addition, in the alternative evaluation stage, three different aggregation operators with different functions are adopted, so the method can be flexibly adapted to different decision-making requirements by adjusting the coefficients.

\section{Conclusions}

Developing sustainable construction industry chain is a key to enhance competitiveness and achieve sustainable development of construction enterprises. Supplier selection is an important choice at the beginning of the life cycle for the construction industry. To solve this problem, an integrated MCDM model was proposed which combines the improved SWARA method with DNMA method. In addition, considering the uncertainty brought by the complex decision-making environment, this paper used HFLTSs to represent the evaluation information of experts. To make better use of HFLTSs, a new distance measure named the two-way test distance measure was proposed, and applied in the DNMA method to make the calculation process reasonable. When two HFLEs are different in length, the distance can be calculated without adding elements to the original evaluation values given by experts, which ensures the integrity of evaluation information. The comparative analysis with the 
HFL-WASPAS method and the HFL-TOPSIS method verified the effectiveness of the method. Since the sustainability-related decision problems usually need to consider a variety of criteria, and the development of society brings great uncertainty to the decision-making environment, the MCDM models in the HFL environment have a strong applicability to solve the sustainability-related decision problems. It can effectively determine the weights of criteria and flexibly meet the needs of decision-makers by adjusting the coefficient. The proposed MCDM model can also be applied to other fields.

This method also has some limitations. Although the introduction of two-way test distance measure in DNMA method increases the rationality of calculation and the integrity of information, the calculation intensity will increase with the increase of the number of alternatives. For the problem of large number of alternatives, the calculation cost is relatively large. In the following research, we will consider to explore a method to reduce the amount of calculation under the premise of considering rationality and information integrity. Meanwhile, in the proposed method, the weights of experts were supposed be given in advance. In future research, we will consider to design a model to determine the weights of experts.

Acknowledgment: The work was supported in part by the National Natural Science Foundation of China (Nos. 71771156 and 71971145).

\section{References}

Aghdaie, M. H., Hashemkhani Zolfani, S., \& Zavadskas, E. K. (2013). Decision making in machine tool selection: an integrated approach with SWARA and COPRAS-G methods. Engineering Economics, 24(1), 5-17. https://doi.org/10.5755/j01.ee.24.1.2822

Ansari, Z. N., \& Kant, R. (2017). A state-of-art literature review reflecting 15 years of focus on sustainable supply chain management. Journal of Cleaner Production, 142(4), 2524-2543. https://doi.org/10.1016/j.jclepro.2016.11.023

Beamon, B. M. (1999). Designing the green supply chain. Logistics Information Management, 12(4), 332-342. https://doi. org/10.1108/09576059910284159

Beg, I., \& Rashid, T. (2013). TOPSIS for hesitant fuzzy linguistic term sets. International
Journal of Intelligent Systems, 28(12), 1162-1171. https://doi.org/10.1002/int.21623

Chatterjee, K., Pamucar, D., \& Zavadskas, E. K. (2018). Evaluating the performance of suppliers based on the R'AMATEL-MAIRCA method for green supply chain implementation in electronics industry. Journal of Cleaner Production, 184, 101-129. https://doi. org/10.1016/j.jclepro.2018.02.186

dos Santos, B. M., Godoy, L. P., \& Campos, L. M. S. (2018). Performance evaluation of green suppliers using entropy-TOPSIS-F. Journal of Cleaner Production, 207, 498-509. https://doi.org/10.1016/j.jclepro.2018.09.235

Gehan, E. A. (1965). A generalized twosample wilcoxon test for doubly censored data. Biometrika, 52(3/4), 650. https://doi. org/10.2307/2333721

Keršulienè, V., Zavadskas, E. K., \& Turskis, Z. (2010). Selection of rational dispute resolution method by applying new step-wise weight assessment ratio analysis (SWARA). Journal of Business Economics and Management, 11(2), 243-258. https://doi.org/10.3846/jbem.2010.12

Keshavarz Ghorabaee, M., Zavadskas, E. K., Amiri, M., \& Esmaeili, A. (2016). Multi-criteria evaluation of green suppliers using an extended WASPAS method with interval type-2 fuzzy. Journal of Cleaner Production, 137, 213-229. https://doi.org/10.1016/j.jclepro.2016.07.031

Liao, H. C., Gou, X. J., Xu, Z. S., Zeng, X. J., \& Herrera, F. (2020). Hesitancy degree-based correlation measures for hesitant fuzzy linguistic term sets and their applications in multiple criteria decision making. Information Sciences, 508, 275-292. https://doi.org/10.1016/j.ins.2019.08.068

Liao, H. C., \& Wu, X. L. (2020). DNMA: A double normalization-based multiple aggregation method for multi-expert multicriteria decision making. Omega, 94, 102058. https://doi.org/10.1016/j.omega.2019.04.001

Liao, H. C., \& Xu, Z. S. (2015). Approaches to manage hesitant fuzzy linguistic information based on the cosine distance and similarity measures for HFLTSs and their application in qualitative decision making. Expert Systems with Applications, 42(12), 5328-5336. https://doi.org/10.1016/j.eswa.2015.02.017

Liao, H. C., Xu, Z. S., Herrera-Viedma, E., \& Herrera, F. (2018). Hesitant fuzzy linguistic term set and its application in decision making: a state-of-the-art survey. International Journal of Fuzzy Systems, 20(7), 2084-2110. https://doi.org/10.1007/s40815-017-0432-9 
Liao, H. C., Xu, Z. S., \& Zeng, X. J. (2014). Distance and similarity measures for hesitant fuzzy linguistic term sets and their application in multi-criteria decision making. Information Sciences, 271, 125-142. https://doi.org/10.1016/j.ins.2014.02.125

Liao, H. C., Xu, Z. S., \& Zeng, X. J. (2015a). Hesitant fuzzy linguistic VIKOR method and its application in qualitative multiple criteria decision making. IEEE Transactions on Fuzzy Systems, 23(5), 1343-1355. https://doi. org/10.1109/tfuzz.2014.2360556

Liao, H. C., Xu, Z. S., Zeng, X. J., \& Merigó, J. M. (2015b). Qualitative decision making with correlation coefficients of hesitant fuzzy linguistic term sets. KnowledgeBased Systems, 76, 127-138. https://doi. org/10.1016/j.knosys.2014.12.009

Lo, H. W., Liou, J. J. H., Wang, H. S., \& Tsai, Y.S. (2018). An integrated model for solving problems in green supplier selection and order allocation. Journal of Cleaner Production, 190, 339-352. https://doi.org/10.1016/j.jclepro.2018.04.105

Matić, B., Jovanović, S., Das, D. K., Zavadskas, E. K., Stević, T., Sremac, S., \& Marinković, M. (2019). A new hybrid MCDM model: sustainable supplier selection in a construction company. Symmetry, 11(3), 353. https://doi.org/10.3390/sym11030353

Ren, R. X., Liao, H. C., Al-Barakati, A., \& Cavallaro, F. (2019). Electric vehicle charging station site selection by an integrated hesitant fuzzy SWARA-WASPAS method. Transformations in Business \& Economics, 18(47), 103-123.

Rodríguez, R. M., Martinez, L., \& Herrera, F. (2012). Hesitant fuzzy linguistic term sets for decision making. IEEE Transactions on Fuzzy Systems, 20(1), 109-119. https://doi. org/10.1109/tfuzz.2011.2170076

Rouyendegh, B. D., Yildizbasi, A., \& Üstünyer, P. (2020). Intuitionistic Fuzzy TOPSIS method for green supplier selection problem. Soft Computing, 24(3), 2215-2228. https://doi. org/10.1007/s00500-019-04054-8

Ruzgys, A., Volvačiovas, R., Ignatavičius, Č., \& Turskis, Z. (2014). Integrated evaluation of external wall insulation in residential buildings using SWARA-TODIM MCDM method. Journal of Civil Engineering and Management, 20(1), 103-110. https://doi.org/10.3846/13923730.20 13.843585

Seth, D., Nemani, V. K., Pokharel, S., \& Al Sayed, A. Y. (2017). Impact of competitive conditions on supplier evaluation: a construction supply chain case study. Production Planning \& Control, 29(3), 217-235. https://doi.org/10.108 0/09537287.2017.1407971

Tosarkani, B. M., \& Amin, S. H. (2018). A multi-objective model to configure an electronic reverse logistics network and third party selection. Journal of Cleaner Production, 198, 662-682. https://doi.org/10.1016/j. jclepro.2018.07.056

Tüysüz, F., \& Şimşek, B. (2017). A hesitant fuzzy linguistic term sets-based AHP approach for analyzing the performance evaluation factors: an application to cargo sector. Complex \& Intelligent Systems, 3, 167-175. https://doi. org/10.1007/s40747-017-0044-x

Wang, T. K., Zhang, Q., Chong, H. Y., \& Wang, X. (2017). Integrated Supplier Selection Framework in a Resilient Construction Supply Chain: An Approach via Analytic Hierarchy Process (AHP) and Grey Relational Analysis (GRA). Sustainability, 9(2), 289. https://doi. org/10.3390/su9020289

Wu, Q., Zhou, L. G., Chen, Y., \& Chen, H. Y. (2019). An integrated approach to green supplier selection based on the interval type2 fuzzy best-worst and extended VIKOR methods. Information Sciences, 502, 394-417. https://doi.org/10.1016/j.ins.2019.06.049

Yin, S., \& Li, B. (2018). Matching management of supply and demand of green building technologies based on a novel matching method with intuitionistic fuzzy sets. Journal of Cleaner Production, 201, 748-763. https://doi.org/10.1016/j.jclepro.2018.08.055

Zadeh, L. A. (1965). Fuzzy sets. Information and Control, 8(3), 338-353. https://doi. org/10.1016/S0019-9958(65)90241-x

Zarbakhshnia, N., Soleimani, H., \& Ghaderi, H. (2018). Sustainable third-party reverse logistics provider evaluation and selection using fuzzy SWARA and developed fuzzy COPRAS in the presence of risk criteria. Applied Soft Computing, 65, 307-319. https://doi.org/10.1016/j.asoc.2018.01.023

Zavadskas, E. K., Turskis, Z., Antucheviciene, J., \& Zakarevicius, A. (2012). Optimization of weighted aggregated sum product assessment. Electronics and Electrical Engineering, 122(6), 3-6. https://doi. org/10.5755/j01.eee.122.6.1810

Zhang, Z. M., \& Wu, C. (2014). Hesitant fuzzy linguistic aggregation operators and their applications to multiple criteria group decision 


\section{Business Administration and Management}

making. Journal of Intelligent \& Fuzzy Systems, 26(5), 2185-2202. https://doi.org/10.3233/IFS130893

Zhu, B., Xu, Z. S., \& Xia, M. M. (2012). Hesitant fuzzy geometric Bonferroni means. Information Sciences, 205, 72-85. https://doi. org/10.1016/j.ins.2012.01.048
Zolfani, S. H., Yazdani, M., \& Zavadskas, E. K. (2018). An extended stepwise weight assessment ratio analysis (SWARA) method for improving criteria prioritization process. Soft Computing, 22(22), 7399-7405. https://doi. org/10.1007/s00500-018-3092-2

\section{Appendix}

Suppose that $H_{S}^{1}=\left\{S_{\alpha}^{1}, \ldots, s_{t}^{1} \ldots, s_{\beta}^{1}\right\}$ and $H_{S}^{2}=\left\{S_{\delta}^{2}, \ldots, s_{t}^{2} \ldots, s_{\gamma}^{2}\right\}$. According to formula 8 , we have

$$
\begin{aligned}
& d\left(H_{S}^{1}, H_{S}^{3}\right)=\left|\frac{\sum_{t_{1}=\alpha}^{\beta} \sigma_{s_{t_{1}}}^{+}}{\sum_{t_{1}=\alpha}^{\beta} \sigma_{s_{t_{1}}}^{+}+\sum_{t_{1}=\alpha}^{\beta} \sigma_{s_{t_{1}}}^{-}}-\frac{\sum_{t_{3}=\varphi}^{\eta} \sigma_{s_{t_{3}}}^{+}}{\sum_{t_{3}=\varphi}^{\eta} \sigma_{s_{t_{3}}}^{+}+\sum_{t_{3}=\varphi}^{\eta} \sigma_{s_{t_{3}}}^{-}}\right| \\
& =\left|\frac{\sum_{t_{1}=\alpha}^{\beta} \sigma_{s_{t_{1}}}^{+}}{\sum_{t_{1}=\alpha}^{\beta} \sigma_{s_{t_{1}}}^{+}+\sum_{t_{1}=\alpha}^{\beta} \sigma_{s_{t_{1}}}^{-}}-\frac{\sum_{t_{2}=\delta}^{\gamma} \sigma_{s_{t_{2}}}^{+}}{\sum_{t_{2}=\delta}^{\gamma} \sigma_{s_{t_{2}}}^{+}+\sum_{t_{2}=\delta}^{\gamma} \sigma_{s_{t_{2}}}^{-}}+\frac{\sum_{t_{2}=\delta}^{\gamma} \sigma_{s_{t_{2}}}^{+}}{\sum_{t_{2}=\delta}^{\gamma} \sigma_{s_{t_{2}}}^{+}+\sum_{t_{2}=\delta}^{\gamma} \sigma_{s_{t_{2}}}^{-}}-\frac{\sum_{t_{3}=\varphi}^{\eta} \sigma_{s_{t_{3}}}^{+}}{\sum_{t_{3}=\varphi}^{\eta} \sigma_{s_{t_{3}}}^{+}+\sum_{t_{3}=\varphi}^{\eta} \sigma_{s_{t_{3}}}^{-}}\right| \\
& \leq\left|\frac{\sum_{t_{1}=\alpha}^{\beta} \sigma_{s_{t_{1}}}^{+}}{\sum_{t_{1}=\alpha}^{\beta} \sigma_{s_{t_{1}}}^{+}+\sum_{t_{1}=\alpha}^{\beta} \sigma_{s_{t_{1}}}^{-}}-\frac{\sum_{t_{2}=\delta}^{\gamma} \sigma_{s_{t_{2}}}^{+}}{\sum_{t_{2}=\delta}^{\gamma} \sigma_{s_{t_{2}}}^{+}+\sum_{t_{2}=\delta}^{\gamma} \sigma_{s_{t_{2}}}^{-}}\right|+\left|\frac{\sum_{t_{2}=\delta}^{\gamma} \sigma_{s_{t_{2}}}^{+}}{\sum_{t_{2}=\delta}^{\gamma} \sigma_{s_{t_{2}}}^{+}+\sum_{t_{2}=\delta}^{\gamma} \sigma_{s_{t_{2}}}^{-}}-\frac{\sum_{t_{3}=\varphi}^{\eta} \sigma_{s_{t_{3}}}^{+}}{\sum_{t_{3}=\varphi}^{\eta} \sigma_{s_{t_{3}}}^{+}+\sum_{t_{3}=\varphi}^{\eta} \sigma_{s_{t_{3}}}^{-}}\right| \\
& =d\left(H_{S}^{1}, H_{S}^{2}\right)+d\left(H_{S}^{2}, H_{S}^{3}\right) \\
& \Rightarrow d\left(H_{S}^{1}, H_{S}^{2}\right)+d\left(H_{S}^{2}, H_{S}^{3}\right)>d\left(H_{S}^{1}, H_{S}^{3}\right) .
\end{aligned}
$$

